\title{
Inhibitory associations between neutral stimuli in flavor-aversion conditioning
}

\author{
A. ESPINET and J. A. IRAOLA \\ Universidad del Pais Vasco, San Sebastian, Spain \\ and \\ C. H. BENNETT and N. J. MACKINTOSH \\ University of Cambridge, Cambridge, England
}

\begin{abstract}
In Experiments 1 and 2, rats were exposed to two compound flavors, AX and BX, containing one flavor in common $(\mathrm{X})$. Following this exposure phase, an aversion was conditioned to $\mathrm{A}$ in the experimental group by pairing its consumption with an injection of lithium, while a control group drank A without being poisoned. The effect of this treatment was to establish $\mathrm{B}$ as a conditioned inhibitor. In Experiment 1, experimental animals were slower than controls to condition an aversion to $B$ when its consumption was paired with lithium (a retardation test of conditioned inhibition). In Experiment 2, B alleviated the suppression of intake of another flavor previously paired with lithium (a summation test). Experiments 3 and 4 established that these effects depended upon prolonged prior exposure to AX and BX.
\end{abstract}

In their theory of stimulus representation, McLaren, Kaye, and Mackintosh (1989) suggested that exposure to two compound stimuli ( $\mathrm{AX}$ and $\mathrm{BX}$ ), containing a common element $X$, would permit the establishment of two types of associations between the elements of each compound. The first would be excitatory associations between the common element $\mathrm{X}$ and each unique element, $\mathrm{A}$ and $\mathrm{B}$. The existence of such associations is evident from studies such as that of Rescorla and Cunningham (1978), employing compound flavors. Their effect will presumably be to enhance generalization between the two compounds: if AX is paired with an unconditioned stimulus (US), the ability of $X$ to retrieve a representation of $B$ could result in excitatory conditioning to $\mathrm{B}$ as well as to $\mathrm{A}$ on this trial. Acquired equivalence effects of this sort have been demonstrated by Honey and Hall $(1989,1991)$.

It is well established, however, that prolonged exposure to $\mathrm{AX}$ and $\mathrm{BX}$ will often facilitate subsequent discrimination, rather than increase generalization between them (Hall, 1991). McLaren et al. (1989) attribute this perceptual learning effect, in part, to differences in the associability of the common (X) and unique (A and B) elements, which occur as a consequence of greater latent inhibition of the former than of the latter. Several studies have provided good evidence for such a suggestion (e.g., Mackintosh, Kaye, \& Bennett, 1991; Rodrigo, Chamizo, McLaren, $\&$ Mackintosh, 1994). However, in a series of experiments on flavor-aversion conditioning, Mackintosh et al. (1991,

This research was supported by grants from Kutxa-UPV/EHU to A.E. and from the Science and Engineering Research Council to N.J.M. Requests for reprints should be sent to A. Espinet, Facultad de Psicologia, Universidad del Pais Vasco, Apdo. 1249, 20080-San Sebastian, Spain. see Experiments 3 and 4) concluded that such differential latent inhibition of common and unique elements could not be the only explanation of perceptual learning. They suggested that one additional mechanism was provided by a second set of associations that are formed between the elements of $A X$ and $B X$-specifically, inhibitory associations between $\mathrm{A}$ and $\mathrm{B}$. The establishment of excitatory associations between common and unique elements may cause $\mathrm{X}$ to retrieve a representation of $\mathrm{B}$ on $\mathrm{AX}$ trials (and of A on BX trials), but the presence of A signals the absence of the otherwise expected $B$ (just as the presence of $B$ signals the absence of the otherwise expected A), and according to standard associative theory, this should lead to the eventual establishment of inhibitory associations between A and B. Such associations should then counteract the increased generalization produced by excitatory associations between common and unique elements.

As Hall (1991) has noted, there is no direct evidence for the existence of such inhibitory associations. What would such evidence look like? One possible experimental test would be to pair A with a US, and then attempt secondorder conditioning of $\mathrm{B}$ by pairing $\mathrm{B}$ with $\mathrm{A}$. Another would be to establish second-order conditioning to $\mathrm{C}$, following first-order conditioning to $\mathrm{A}$, and then to show that conditioned responding to C (presumably mediated by C's ability to retrieve a representation of A) was suppressed if $C$ was presented in conjunction with $B$. Both strategies depend on reliable second-order conditioning and, after several attempts, we have abandoned them because, in our laboratories, second-order conditioning of flavor aversions has proved difficult to establish. We report here the results of a quite different approach. In two experiments, we show that after rats are exposed to $\mathrm{AX}$ and $\mathrm{BX}$, pairing $\mathrm{A}$ with a US will establish B as a Pavlovian conditioned inhibitor of that US. Experiment 1 employed a retardation test of 
Table 1

\begin{tabular}{cccc}
\multicolumn{4}{c}{ Table 1 } \\
Design of Experiment 1 \\
\hline Group & Pre-exposure & Conditioning & Retardation Test \\
\hline $\mathrm{X}+$ & $(\mathrm{Sal}+\mathrm{Sac}),(\mathrm{Ac}+\mathrm{Sac})$ & $\mathrm{Sac} \rightarrow \mathrm{LiCl}(0.3 \mathrm{M})$ & $\mathrm{Sal} \rightarrow \mathrm{LiCl}(0.15 \mathrm{M})$ \\
$\mathrm{A}+$ & $(\mathrm{Sal}+\mathrm{Sac}),(\mathrm{Ac}+\mathrm{Sac})$ & $\mathrm{Ac} \rightarrow \mathrm{LiCl}(0.3 \mathrm{M})$ & $\mathrm{Sal} \rightarrow \mathrm{LiCl}(0.15 \mathrm{M})$ \\
$\mathrm{A}$ & $(\mathrm{Sal}+\mathrm{Sac}),(\mathrm{Ac}+\mathrm{Sac})$ & $\mathrm{Ac} \rightarrow \mathrm{Saline}$ & $\mathrm{Sal} \rightarrow \mathrm{LiCl}(0.15 \mathrm{M})$ \\
\hline Note-Sal, saline; Ac, acid; Sac, saccharin
\end{tabular}

conditioned inhibition, while Experiment 2 employed a summation test. Experiments 3 and 4 show that it is exposure to $\mathrm{AX}$ and $\mathrm{BX}$ that is necessary for these effects to occur.

\section{EXPERIMENT 1}

\section{Method}

Subjects and Apparatus. The subjects were 30 experimentally naive male Wistar rats, weighing $200-252 \mathrm{~g}$ at the beginning of the experiment. Upon their arrival in the laboratory, they were housed in individual cages, with free access to food and water for 2 weeks. During the 3 rd week, they were placed on a deprivation schedule which allowed them 15 -min daily access to water. Over the last 3 days of this week, and, except for a recovery period before the final retardation test, for the remainder of the experiment, their only access to fluid occurred in 10 rectangular black metal cages, measuring $20 \times 20 \times 40 \mathrm{~cm}$, with mesh roof and floor. The solutions used in the experiment were presented in glass bottles, furnished with $3.5-\mathrm{cm}$-long metal spouts, which were inserted through one of the walls of the cages.

Procedure. The experiment began at the end of the week of deprivation (see previous section). The design is shown in Table 1. Ten subjects were assigned randomly to each of three groups, $\mathrm{X}+\mathrm{A}+$, and $A$ (these designations refer to the treatment of the three groups in the second phase of the experiment).

The solutions contained: $0.3 \%$ citric acid (referred to as $\mathrm{A}$, to maintain the notation used in the introductory section); $0.5 \%$ saline (referred to as B); and $0.15 \%$ saccharin (referred to as X). All concentrates were dissolved in distilled water. From these solutions, two compound flavors were produced, by mixing one part of the saccharin solution (which served as the common element) with either four parts of the acid solution (AX) or four parts of the saline solution (BX). Thus saccharin constituted the same proportion of both compound solutions.

The preexposure phase of the experiment lasted 12 days. Half of the subjects in each group were exposed on odd days to bottles containing the acid-saccharin (AX) solution, and on even days to bottles containing the saline-saccharin (BX) solution. The remaining subjects received the two compound solutions in the opposite order. Throughout this and subsequent phases of the experiment, daily sessions lasted for $15 \mathrm{~min}$.

The day following the end of preexposure was a conditioning session. Subjects in Group X+ drank saccharin (X) for $15 \mathrm{~min}$, immediately followed by an intraperitoneal injection of $10 \mathrm{ml}$ per kg body weight of $0.3 \mathrm{M}$ lithium chloride. Subjects in Group A+ received a similar injection immediately following a $15-\mathrm{min}$ period during which they consumed acid (A). Subjects in the control group, A, also drank the acid solution for $15 \mathrm{~min}$, and this was followed by a $10-\mathrm{ml} / \mathrm{kg}$ injection of physiological saline. The injections were administered in a room adjacent to the experimental roon. Following this session, all subjects remained in their home cages with 15 -min daily access to water for one week

This was followed by the retardation test, which consisted of four conditioning sessions on alternate days. On each conditioning trial, all subjects had access to the saline solution (B) for $15 \mathrm{~min}$, immediately followed by a $10-\mathrm{ml} / \mathrm{kg}$ injection of $0.15 \mathrm{M}$ lithium chloride.
On the day after each conditioning trial, the subjects drank water for $15 \mathrm{~min}$ in the experimental cages.

Two days after the end of this retardation test, there was a single 15-min test session in which each group was presented with the solution they had drunk on the initial conditioning trial (i.e., saccha$\operatorname{rin}[\mathrm{X}]$ for Group $\mathrm{X}+$, and acid [A] for Groups $\mathrm{A}+$ and $\mathrm{A}$ ). This provided a measure of the conditioning that had occurred on this trial.

\section{Results}

A significance level of $p<.05$ is adopted throughout the paper. The mean amount of the acid-saccharin (AX) solution drunk over the last three preexposure trials was $12.7,13.8$, and $14.1 \mathrm{ml}$ for Groups $\mathrm{X}+, \mathrm{A}+$, and $\mathrm{A}$, respectively. There was no difference between the three groups $[F(2,27)=1.4]$, nor was there any difference in their consumption of the saline-saccharin (BX) solution over this period: Groups X+, A+, and A drank 22.7, 23.6, and $23.3 \mathrm{ml}$, respectively $(F<1)$.

Figure 1 shows each group's mean consumption of saline (B) over the course of the retardation test. An overall analysis of variance (ANOVA) revealed significant effects of group $[F(2,27)=20.4]$ and day $[F(3,25)=13.2]$, and a significant interaction between the two $[F(6.52)=$ 7.49]. In view of this interaction, separate analyses were conducted on the scores for each day. These statistical analyses revealed no difference between groups on Day 1 $[F(2,27)=2.3]$, but a significant difference on each of Days 2, 3, and $4\left(F_{\min }=14.9\right)$. Newman-Keuls pairwise comparisons showed that on Day 2, there was no difference between Groups $A+$ and $A$, both of which differed from Group X+. On Days 3 and 4, Group A+ drank significantly more than Groups $A$ and $X+$, which did not differ from one another.

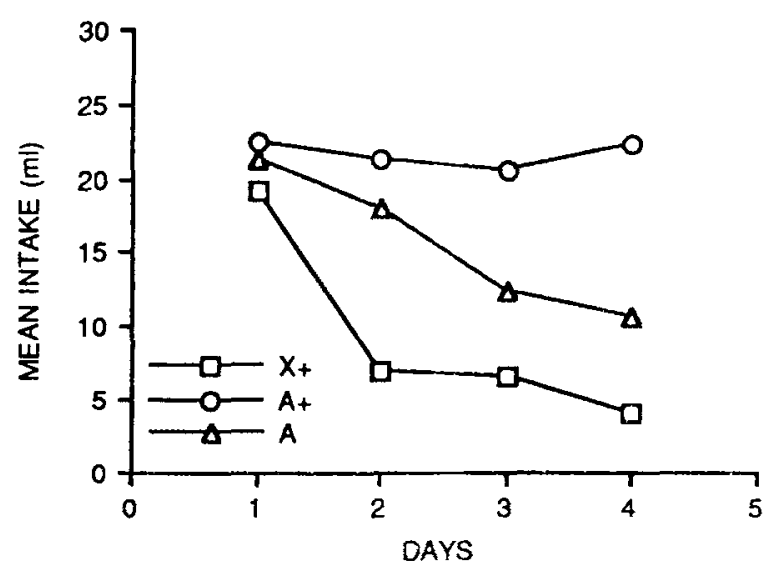

Figure 1. Mean intake of saline over 4 days of conditioning in the retardation test of Experiment 1. 
Within-subject analyses established that in Group A+, there was no evidence of any decline in consumption from Day 1 to Day 4; comparison of Day 1 with each subsequent day yielded no significant differences $\left(t_{\max }=1.5\right)$. In Group A, there was no decline in consumption from Day 1 to Day $2(t=1.8)$, but on both Days 3 and 4 , animals drank less than on Day $1\left(t_{\min }=3.3\right)$. Group $X+$ drank less on all three subsequent days than they did on Day $1\left(t_{\min }=5.0\right)$.

Finally, comparisons of the amount consumed on the initial conditioning trial and the final test trial revealed that subjects in both Groups $\mathrm{A}+$ and $\mathrm{X}+$ drank less acid and saccharin, respectively, on the final test $(t=2.7$ and 10.5 , respectively), while Group A, which had received an injection of physiological saline, showed a significant increase in consumption of acid $(t=2.2)$.

\section{Discussion}

The three groups differed significantly in their acquisition of an aversion to saline (B) when its consumption was paired with a lithium injection. Since they were treated identically during the preexposure phase of the experiment, these differences cannot be attributed to any difference in exposure to $\mathrm{B}$ (or any other solution); in particular, they cannot be due to any difference in latent inhibition to $B$. The only difference in the treatment of the three groups occurred on their single conditioning trial in the second phase of the experiment. The finding that Group $\mathrm{X}+$ subsequently conditioned an aversion to $B$ more rapidly than the control group, $\mathrm{A}$, which received no lithium injection on this trial, is presumably attributable to sensory preconditioning: The establishment of an association between $\mathrm{B}$ and $X$ during preexposure, followed by conditioning to $X$. resulted in some aversion to $B$ before $B$ itself was paired with lithium. However, the finding that Group A + conditioned an aversion to B more slowly than Group A is the most interesting result of this experiment. Retardation of excitatory conditioning is one diagnostic criterion of prior inhibitory conditioning. One interpretation of this difference, then, is that in Group A+, B became a conditioned inhibitor of the US. Before considering the implications of that interpretation, however, we need further evidence. Experiment 2 was designed to see whether, in Group $\mathrm{A}+, \mathrm{B}$ would pass a summation test of conditioned inhibition.

\section{EXPERIMENT 2}

\section{Method}

Subjects and Apparatus. The subjects were 20 experimentally naive male Wistar rats, weighing $174-216 \mathrm{~g}$ at the start of the experiment. They were maintained in the same way as those in Experiment 1 , and the experimental apparatus was also the same as before.
Procedure. The subjects were randomly assigned to the two experimental groups, $\mathrm{A}+$ and $\mathrm{A}$. The experimental design is shown in Table 2. The same three basic solutions were used as in Experiment 1 , but they were combined in different ways to form two new compound solutions, in order to rule out the possibility that our results might depend on the use of particular compounds. In the present experiment, acid served as the common element (X), and the two compound solutions were made up of either four parts of saccharin (A) or four parts of saline (B) to one part of acid solution. A fourth solution $(Y)$, which served as a $C S+$ in the final phase of the experiment, consisted of $0.01 \%$ quinine. For the summation test, $5 \mathrm{~g}$ of salt (B) was added to $1 \mathrm{~L}$ of this quinine solution.

After the initial phase of water deprivation, preexposure proceeded as in Experiment 1, with 6 days of preexposure to saccharinacid $(\mathrm{AX})$ alternating with 6 days of preexposure to saline-acid (BX). Following preexposure, there were 2 conditioning days, separated by a recovery day. On each conditioning trial, all subjects had access to saccharin (A) for $15 \mathrm{~min}$, followed immediately, for Group $\mathrm{A}+$, by an intraperitoneal injection of $10 \mathrm{ml} / \mathrm{kg}$ of $0.3 \mathrm{M}$ lithium chloride, and for the control group, A, by an injection of a similar amount of physiological saline. There followed a 2 nd recovery day, then a test of animals' aversion to saccharin.

Following 3 further recovery days, on which the subjects had access to water for $15 \mathrm{~min}$, there was a second conditioning phase, designed to condition an aversion to quinine. All subjects had access to quinine for $15 \mathrm{~min}$ on 2 consecutive days, followed. on the 2 nd day, by an intraperitoneal injection of $10 \mathrm{ml} / \mathrm{kg}$ of $0.3 \mathrm{M}$ lithium chloride. After a recovery day with access to water for $15 \mathrm{~min}$, they received a 15 -min test trial with access to quinine. a further recovery day, and a final test trial on which they had access to the quinine + saline (BY) solution for $15 \mathrm{~min}$.

\section{Results and Discussion}

There was no difference in the mean consumption of saccharin-acid $(A X)$ averaged over the last 3 days of preexposure, which was $12.7 \mathrm{ml}$ in Group $\mathrm{A}+$ and $12.6 \mathrm{ml}$ in Group A. There was, equally, no difference in the two groups' consumption of saline-acid (BX: 12.8 and 13.7 ml, respectively).

There was also no difference in mean consumption between groups on the initial conditioning trial to $\mathrm{A}$, when Group A+ drank $15.2 \mathrm{ml}$ and Group A drank $14.7 \mathrm{ml}$. On the second trial, however, consumption in Group A+ declined to $3.4 \mathrm{ml}$, while Group A consumed $15.5 \mathrm{ml}$, and on the final conditioning trial, these amounts were $0.79 \mathrm{ml}$ and $15.0 \mathrm{ml}$, respectively ( $t=9.5$ and 12.3 , respectively).

Mean consumption of quinine on the conditioning trial was $7.5 \mathrm{ml}$ and $10.6 \mathrm{ml}$ in Groups $\mathrm{A}+$ and $\mathrm{A}$, respectively; this difference was just significant $(t=2.27)$. Both groups showed a decline in their consumption of quinine from this trial to the test trial after conditioning $\left(t_{\text {min }}=3.6\right)$.

Figure 2 shows, for each group, the mean consumption of quinine alone on this trial, and the consumption of quinine + saline (BY) on the following test trial. In spite of the appearance of a difference between the two groups in their consumption of quinine, this difference was not sig-

Table 2

Design of Experiment 2

\begin{tabular}{llccc}
\hline Group & \multicolumn{1}{c}{ Pre-exposure } & Conditioning 1 & Conditioning 2 & Summation Test \\
& $(\mathrm{Sal}+\mathrm{Ac}),(\mathrm{Sac}+\mathrm{Ac})$ & $\mathrm{Sac} \rightarrow \mathrm{LiCl}$ & Quin $\rightarrow \mathrm{LiCl}$ & (Sal + Quin) \\
$\mathrm{A}$ & $(\mathrm{Sal}+\mathrm{Ac}),(\mathrm{Sac}+\mathrm{Ac})$ & $\mathrm{Sac} \rightarrow \mathrm{Saline}$ & Quin $\rightarrow \mathrm{LiCl}$ & (Sal + Quin) \\
\hline
\end{tabular}

Note-Sal, saline; Ac, acid; Sac, saccharin; Quin, quinine. 


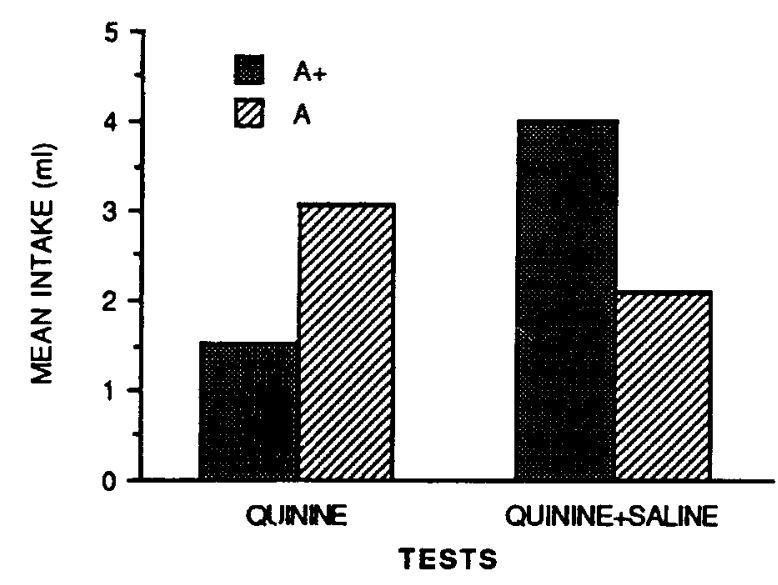

Figure 2. Mean intake of quinine alone and of quinine + saline in the summation test of Experiment 2.

nificant $(t=0.7)$. However, on the quinine + saline test trial, Group A + drank significantly more than Group A $(t=2.4)$. Within-subject comparisons revealed a significant difference in Group A+ in subjects' consumption of quinine and of quinine + saline $(t=4.95)$, but no such difference in Group A $(t=0.49)$.

These test results are exactly what would be expected if $\mathrm{B}$ were a conditioned inhibitor in Group $\mathrm{A}+$, but not in Group A: In the former group, the presence of B alleviated the suppression of intake of quinine induced by pairing it with lithium, while in the latter group, it had no such effect.

\section{EXPERIMENT 3}

The results of Experiments 1 and 2 suggest that following exposure to two flavors, $\mathrm{A}$ and $\mathrm{B}$, the conditioning of an aversion to $A$ can turn $B$ into a conditioned inhibitor, that passes both retardation (Experiment 1) and summation (Experiment 2) tests of conditioned inhibition. But they do not establish the specific conditions of prior exposure to A and B that are necessary to generate such an effect. According to the analysis of McLaren et al. (1989), the establishment of inhibitory associations between $A$ and $B$ depends on their being repeatedly presented, on separate occasions, but in the presence of other common cues. The preexposure phase of both Experiments 1 and 2 satisfied the requirement by alternating $\mathrm{AX}$ and $\mathrm{BX}$ trials. However, since all animals in these experiments were subjected to this procedure, we do not know whether it was critical; perhaps any sort of preexposure to A and B would have produced these results. Less plausibly, it might even be the case that no preexposure is necessary.

In Experiment 3, we compared the effect of exposure to $\mathrm{AX}$ and $\mathrm{BX}$ with that of comparable exposure to $\mathrm{A}$ and $\mathrm{B}$ alone. According to McLaren et al. (1989), the former group should show stronger evidence than the latter of conditioned inhibition to $\mathrm{B}$, following excitatory conditioning to A. Inhibitory associations will develop between $A$ and $B$ to the extent that each occurs in the presence of stimuli that retrieve a representation of the (absent) other. Although contextual stimuli may provide such retrieval cues, the presence of an explicit common flavor, X, must increase any such effect. In Experiment 4 , we varied the amount of exposure to $\mathrm{AX}$ and $\mathrm{BX}$. The theory predicts that the initial associations established by such exposure will be excitatory ones, between $A$ and $X$ and between $B$ and $X$. Only after such excitatory associations have been formed will it be possible to start forming inhibitory associations between A and B. It follows that a small amount of exposure to $\mathrm{AX}$ and $\mathrm{BX}$ would be insufficient to produce the effects observed in Experiments 1 and 2, and might even enhance generalization between $A$ and B. Only prolonged exposure would produce inhibitory effects.

\section{Method}

Subjects and Apparatus. The subjects were 27 male Wistar rats, weighing $395-550 \mathrm{~g}$ at the beginning of the experiment. They had previously participated in an experiment on conditioned suppression, employing lights and tones. One week before the start of the present experiment, they were placed on a deprivation schedule which allowed them access to water for $15 \mathrm{~min}$ each day. The apparatus and general procedure were the same as in Experiment 1 . The solutions employed were: $A$, citric acid $(3 \mathrm{~g} / \mathrm{L})$; and $\mathrm{B}$, saline $(3 \mathrm{~g} / \mathrm{L})$; both solutions were, in some cases, mixed with $\mathrm{X}$. liquid saccharin (Dagutan) at $15 \mathrm{ml} / \mathrm{L}$.

Procedure. The experimental design is shown in Table 3. During the 12 days of preexposure, all subjects had access to flavored solutions for 15 min each day. For Groups AX-BX and C, these solutions were saline-saccharin on odd days and acid-saccharin on even days. For Group A-B, the solutions were saline on odd days and acid on even days.

On the day following the last preexposure trial, all subjects drank acid (A) for 15 min. For Groups AX-BX and A-B, this was immediately followed by an intraperitoneal injection of $10 \mathrm{ml} / \mathrm{kg}$ of $0.3 \mathrm{M}$ lithium chloride given in an adjacent room; for Group C, the injection was of physiological saline.

Following this conditioning session, all subjects remained in their home cages for a week, with 20-min daily access to water. This was followed by a retardation test of conditioning to salıne (B). On Days $1,3,5$, and 7 , the subjects drank saline for $15 \mathrm{~min}$, followed immediately, on Days 1,3, and 5, by an injection of $0.15 \mathrm{M}$ lithium chloride. On even days, the subjects drank water. On Day 9 , all subjects received a 15-min test for their consumption of acid (A).

Table 3

Design of Experiment 3

\begin{tabular}{|c|c|c|c|}
\hline Group & Pre-exposure & Conditioning & Retardation Test \\
\hline $\mathrm{AX}-\mathrm{BX}$ & $(\mathrm{Sal}+\mathrm{Sac}),(\mathrm{Ac}+\mathrm{Sac})$ & $\mathrm{Ac} \rightarrow \mathrm{LiCl}(0.3 \mathrm{M})$ & $\mathrm{Sal} \rightarrow \mathrm{LiCl}(0.15 \mathrm{M})$ \\
\hline A-B & $(\mathrm{Sal}),(\mathrm{Ac})$ & $\mathrm{Ac} \rightarrow \mathrm{LiCl}(0.3 \mathrm{M})$ & $\mathrm{Sal} \rightarrow \operatorname{LiCl}(0.15 \mathrm{M})$ \\
\hline $\mathrm{C}$ & $(\mathrm{Sal}+\mathrm{Sac}),(\mathrm{Ac}+\mathrm{Sac})$ & $\mathrm{Ac} \rightarrow$ Saline & $\mathrm{Sal} \rightarrow \mathrm{LiCl}(0.15 \mathrm{M})$ \\
\hline
\end{tabular}

Note-Sal, saline; Ac, acid; Sac, saccharin. 


\section{Results and Discussion}

On the 3 last days of preexposure, Groups AX-BX and $\mathrm{C}$ drank 24.8 and $24.3 \mathrm{ml}$ of saline-saccharin, and Group A-B drank $21.5 \mathrm{ml}$ of saline. These differences were significant $[F(2,24)=4.21]$, due to the slightly greater consumption of saline-saccharin than of saline alone. Groups $\mathrm{AX}-\mathrm{BX}$ and $\mathrm{C}$ drank 8.7 and $9.6 \mathrm{ml}$ of acid-saccharin, while Group A-B drank $8.2 \mathrm{ml}$ of acid, but these differences were not significant $(F<1)$. There was, equally, no difference between the three groups in their consumption of acid on their conditioning trial to $\mathrm{A}(F<1)$.

Figure 3 shows the mean consumption of saline (B) on each day of the retardation test. As can be seen, there was no great difference between the three groups on the first 2 days of conditioning. But by the $3 \mathrm{rd}$ and 4 th days of conditioning, Group AX-BX was drinking rather more than the other two groups. An overall ANOVA revealed no main effect of group $[F(2,24)=2.2]$, but a significant effect of day $[F(3,22)=79.2]$ and a significant interaction between group and day $[F(6,67)=2.67]$. Subsequent analyses revealed no differences between groups on the 1 st and the 2 nd day $[F=1.6$ and $<1$, respectively), but significant differences on both the 3 rd and the 4th day $\left(F_{\min }=5.0\right)$. Newman-Keuls tests established that Group AX-BX differed from each of the other groups on Day 3, and from Group $C$ on Day 4 . No other differences were significant.

Within-subject comparisons over the first 2 days of conditioning established that there was a significant decline in consumption from Day 1 to Day 2 in Group A-B $(t=2.3)$ and a marginal decline in Group $C(t=2.0)$, but no decline in Group AX-BX $(t=1.3)$.

The mean consumption of citric acid $(A)$ on the final test day was $5.1,2.3$, and $10.9 \mathrm{ml}$ in Groups AX-BX, $\mathrm{A}-\mathrm{B}$, and $\mathrm{C}$, respectively $[F(2,24)=19.7]$. NewmanKeuls tests established that Group $C$ drank more than the remaining two groups, which did not differ from one another.

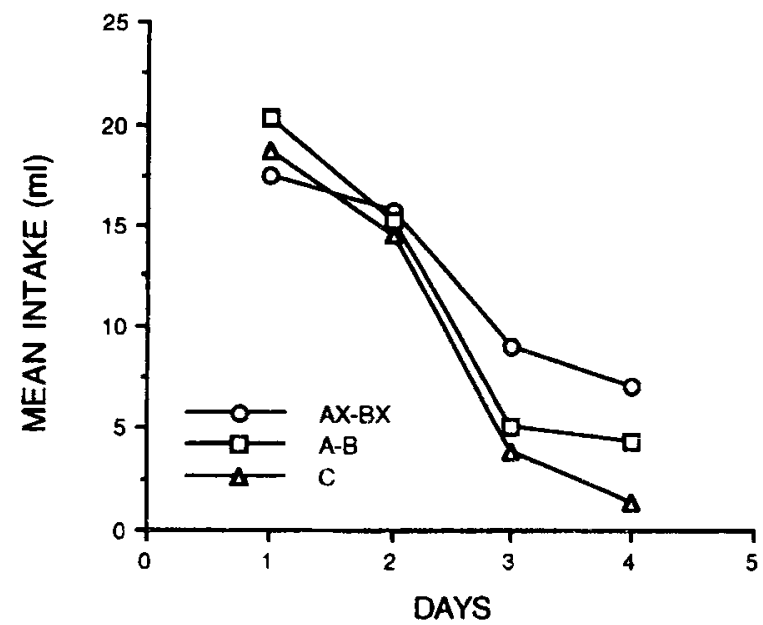

Figure 3. Mean intake of saline over 4 days of conditioning in the retardation test of Experiment 3 .
These results confirm, albeit not quite so dramatically, the retardation effect observed in Experiment 1. Group AX-BX (the equivalent of Group A+ in Experiment 1) conditioned significantly more slowly than Group $\mathrm{C}$ (the equivalent of Group $A$ in Experiment 1). There was no evidence, however, of any retardation effect in Group A-B, which did not differ from the control group on any day. Moreover, the significant difference between Groups AX$\mathrm{BX}$ and $\mathrm{A}-\mathrm{B}$ on the $3 \mathrm{rd}$ day implies that the retardation effect was increased by prior exposure to $A$ and $B$ in the presence of a third, common flavor.

\section{EXPERIMENT 4}

In Experiment 4, we varied the amount of prior exposure to AX and BX. One pair of groups received 4 days of exposure to each compound solution; a second pair received 12 days of exposure to each. This is twice the amount of exposure given in Experiments 1-3, but in this experiment, which was run in a different laboratory, the rats were substantially less thirsty, and thus drank rather less on each trial. One group of each pair, $\mathrm{A}+$, was then conditioned to $\mathrm{A}$, while the other, $\mathrm{AC}$, which served as the control group, was divided into two, with half the animals, as in Experiments 1-3, receiving an immediate injection of physiological saline, and the other half receiving a lithium injection $24 \mathrm{~h}$ later. In the next phase of the experiment, all animals had an aversion conditioned to a fourth solution, quinine, before finally receiving a series of test trials in which they had free access to quinine or to a compound solution of quinine $+B$. This constituted, as in Experiment 2, a summation test of conditioned inhibition to $\mathrm{B}$.

\section{Method}

Subjects and Apparatus. The subjects were 32 male hooded Lister rats weighing $330-385 \mathrm{~g}$ prior to conditioning. They were housed in groups of four and were maintained on a 22.5 -h water-deprivation schedule, with free access to food. The apparatus was housed in a different room and consisted of eight rectangular plastic cages, $30 \times 12.5 \times 11 \mathrm{~cm}$, with wire-mesh floors and ceilings. Fluid was presented through the front of each drinking cage in a $50-\mathrm{ml}$ cylinder with the same metal spout that was used in the home cages.

Procedure. Following initial water deprivation, all animals received 3 days of preliminary training, during which they were placed in the drinking cages with access to water for $15 \mathrm{~min}$. The rats were then randomly divided into four groups of eight, $\mathrm{A} 12+, \mathrm{A} 12 \mathrm{C}$, $\mathrm{A} 4+$, and $\mathrm{A} 4 \mathrm{C}$ (group designations refer to amount of preexposure and treatment during the first conditioning phase).

The solutions used were the following: $2 \%$ lemon ( $2 \%$ lemon by volume Sainsbury's Pure Lemon Juice; $X$ ), which served as the common element during preexposure; $0.00005 \mathrm{M}$ quinine $(\mathrm{Y})$, which served as the excitor for the summation test; and $2 \%$ stcrose and $0.9 \%$ saline $(A$ or $B$ ), which were counterbalanced in terms of the first conditioning phase. Hereafter, A refers to the conditioned flavor, and $B$ refers to the flavor paired with quinine on test.

Over the following 24 days of preexposure, rats in Groups $\mathrm{Al} 2+$ and $A 12 \mathrm{C}$ received 12 alternating presentations of each of the two compound solutions ( $\mathrm{AX}$ and $\mathrm{BX}$ ) for $15 \mathrm{~min}$. Half of the animals in these two groups were exposed to sucrose-lemon flavor on odd days and to saline-lemon flavor on even days. The other half received the opposite arrangement. For the first 16 days of preexposure. ani- 
mals in Groups $\mathrm{A} 4+$ and $\mathrm{A} 4 \mathrm{C}$ had access to water in the drinking cages for 15 min. Beginning on Day 17, animals in these two groups received four alternating presentations of each of the two compound solutions. As before, half of the animals in each group were exposed to sucrose-lemon flavor on odd days and to saline-lemon flavor on even days, while the other half received the two compound solutions in the opposite order.

The day following the end of preexposure was a conditioning trial. On Day 1 of the first conditioning phase (to A), half of the animals in each group had access to sucrose alone for $15 \mathrm{~min}$, while the other half had access to saline alone. For animals in Groups $\mathrm{Al} 2+$ and $\mathrm{A} 4+$, consumption was immediately followed by an intraperitoneal injection of $20 \mathrm{ml} / \mathrm{kg}$ of $0.15 \mathrm{M}$ lithium chloride. For half of the animals in Groups $\mathrm{A} 12 \mathrm{C}$ and $\mathrm{A} 4 \mathrm{C}$ (counterbalanced according to the flavor presented - saline or sucrose), consumption of A was immediately followed by an intraperitoneal injection of $20 \mathrm{ml} / \mathrm{kg}$ of physiological saline, while the other half received the injection of lithium chloride $24 \mathrm{~h}$ later. On the 3rd day of this conditioning phase, the above procedure was repeated exactly.

Following the first conditioning phase, all animals received 3 days of recovery, during which they were placed in the drinking cages and received access to water for $15 \mathrm{~min}$.

On Day 1 of the second conditioning phase (to $\mathrm{Y}$ ), all animals had access to the quinine solution for $15 \mathrm{~min}$, and this was immediately followed by an intraperitoneal injection of $7.5 \mathrm{ml} / \mathrm{kg}$ of $0.15 \mathrm{M}$ lithium chloride. On the second day of this phase, the above procedure was repeated, except that the dosage of lithium chloride was increased to $10 \mathrm{ml} / \mathrm{kg}$.

Finally, 10-min test trials began on the next day, in which all animals were tested for their consumption of quinine alone $(\mathrm{Y})$, and of quinine plus saline or sucrose (BY), whichever had not been presented during the first conditioning phase. These test solutions were presented in the following order: Y, BY, BY, Y.

\section{Results}

The data for 1 animal from Group $\mathrm{A} 12 \mathrm{C}$ (unpaired treatment) were discarded, since this animal failed to condition to quinine (Y).

Mean consumption of sucrose-lemon averaged over the last 2 days of preexposure was $16.84 \mathrm{ml}$ in Group A $12+$, $17.92 \mathrm{ml}$ in Group A12C, $13.56 \mathrm{ml}$ in Group A4+, and $13.34 \mathrm{ml}$ in Group A4C. Consumption of saline-lemon was $14.09 \mathrm{ml}$ in Group A12+, $14.96 \mathrm{ml}$ in Group A12C, $10.59 \mathrm{ml}$ in Group $\mathrm{A} 4+$, and $11.93 \mathrm{ml}$ in Group A4C. An ANOVA (length of preexposure $\times$ Phase 1 conditioning treatment $[\mathrm{LiCl} /$ saline/unpaired $] \times$ compound solution) revealed that animals in the $\mathrm{A} 12$ groups drank more overall than those in the A4 groups $[F(1,25)=49.04]$, and that all animals drank more sucrose-lemon than saline-lemon $[F(1,25)=32.33]$. No other differences were significant $\left(F_{\max }=1.76\right)$.

On the initial conditioning trial to A, Group $\mathrm{A} 12+$ drank $17.50 \mathrm{ml}$, Group A12C drank $15.92 \mathrm{ml}$, Group A4 + drank $14.18 \mathrm{ml}$, and Group A4C drank $16.93 \mathrm{ml}$. On the second conditioning trial, consumption declined in Groups $\mathrm{Al2}+$ and $\mathrm{A} 4+$ to $6.81 \mathrm{ml}$ and $4.75 \mathrm{ml}$, respectively, while Groups A12C and $14 \mathrm{C}$ consumed $16.71 \mathrm{ml}$ and $14.43 \mathrm{ml}$. An ANOVA, with conditioned solution (sucrose or saline) as a factor, revealed that animals in the A12 groups drank more overall than those in the A4 groups $[F(1,19)=5.57]$, and that all animals drank more sucrose than saline $[F(1,19)=22.94]$. There were also main effects of conditioning treatment $[F(2,19)=33.05]$, and first or second conditioning trial $[F(1,19)=49.54]$, and an interaction between the two $[F(2,19)=26.48]$. Newman-Keuls pairwise comparisons of the three conditioning treatments revealed that animals in both control treatments drank significantly more than the conditioned animals, but did not differ from one another. Analysis of simple effects within the interaction showed that conditioning was effective on Trial $2[F(2,19)=80.14]$, and that animals in Groups A12+ and A4+ drank less on the second trial $[F(1,19)=182.00]$, whereas animals in Groups A12C and A4C drank similar amounts on both trials $(F \mathrm{~s}<1)$. There was also an interaction between conditioned solution and trial $[F(1,19)=9.22]$. Analysis of simple effects revealed that animals drank more sucrose than saline on Trial $1[F(1,19)=24.70]$, but similar amounts on Trial $2[F(1,19)=2.78]$, and that animals drank less of both solutions on Trial $2\left[F_{\min }(1,19)=9.78\right]$. Since the conditioned solution (saline or sucrose) was counterbalanced within each group, and the present analysis revealed no interaction between conditioned solution and length of preexposure or conditioning treatment, subsequent analyses are collapsed across this factor.

Mean consumption of water averaged over the 3 days of recovery was $9.10 \mathrm{ml}$ in Group A 12+, $11.35 \mathrm{ml}$ in Group $\mathrm{A} 12 \mathrm{C}, 9.06 \mathrm{ml}$ in Group $\mathrm{A} 4+$, and $11.27 \mathrm{ml}$ in Group A4C. An ANOVA, with recovery day as a factor, revealed an effect of previous conditioning treatment $(\mathrm{LiCl}$, saline, or unpaired) on water consumption $[F(2,25)=17.43]$. Newman-Keuls pairwise comparisons showed that conditioned animals drank less overall than animals from both control treatments, but that animals who received a saline injection also drank less than animals in the unpaired condition. There was an increase in consumption of water over the 3 recovery days $[F(2,50)=35.95]$, and a three-way interaction between length of preexposure, conditioning treatment, and recovery day $[F(4,50)=2.75]$. The important result of this analysis is that animals in Groups $\mathrm{A} 12+$ and $\mathrm{A} 4+$ drank less water over the course of recovery than animals in the two control groups, presumably because of a certain degree of conditioning to the experimental context. Clearly, any contextual conditioning in the experimental groups would work against our prediction for the summation test--that animals in Group Al 2 + would drink more of the compound solution than animals in Group A 12C.

On the initial conditioning trial to quinine, Group $\mathrm{A} 12+$ drank $8.93 \mathrm{ml}$, Group A 12C drank $8.57 \mathrm{ml}$, Group A4+ drank $8.18 \mathrm{ml}$, and Group A4C drank $9.31 \mathrm{ml}$. On the second conditioning trial, consumption declined in all groups, to $4.50 \mathrm{ml}$ in Group $\mathrm{A} 12+, 4.25 \mathrm{ml}$ in Group $\mathrm{A} 4+$, $3.21 \mathrm{ml}$ in Group A12C, and $4.56 \mathrm{ml}$ in Group A4C. An ANOVA revealed a significant decrease in consumption from Trial 1 to Trial $2[F(1,25)=177.78]$ for all animals. No other effects were significant $\left(F_{\max }=1.87\right)$.

The main results of the experiment are shown in Figure 4 . The test data were collapsed across the two control treatments (saline or unpaired) in Groups A12C and A4C, since a preliminary analysis revealed no differences between the two treatments, nor any interaction with any 


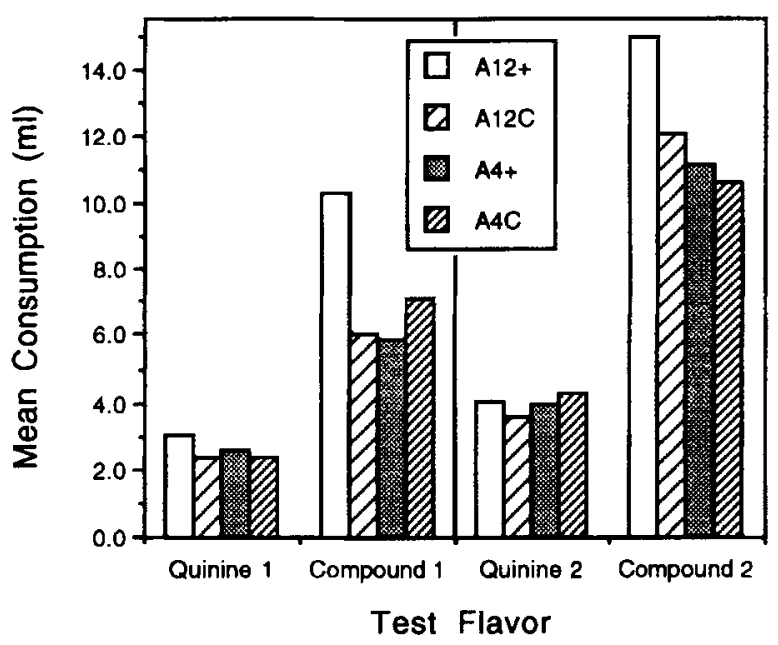

Figure 4. Mean intake of quinine alone and of quinine $+B$ in the summation tests of Experiment 4.

other factor $\left(F_{\max }=2.33\right)$. The figure indicates that while all animals drank similar amounts of quinine alone, animals in Group $\mathrm{A} 12$ + drank more of the compound solution than did those in the other three groups. An ANOVA performed on the data for consumption of quinine alone revealed that all animals drank more on the second test than on the first $[F(1,27)=45.63]$, but no other differences were significant $\left(F_{\max }=1.63\right)$. The critical analysis was performed on difference scores - consumption of the compound solution minus consumption of quinine alons. The ANOVA revealed a significant effect of preexposure $[F(1,27)=5.39]$ and of test day $[F(1,27)=54.02]$. Although the interaction between preexposure and conditioning treatment fell short of significance $[F(1,27)=$ 2.94], analysis of simple effects showed that the critical comparison between Groups $\mathrm{A} 12+$ and $\mathrm{A} 12 \mathrm{C}$ was significant $[F(1,27)=4.66]$, while there was no difference between Groups $\mathrm{A} 4+$ and $\mathrm{A} 4 \mathrm{C}(F<1)$. In addition, the difference score was larger for animals in Group $\mathrm{A} 12+$ than for animals in Group $\mathrm{A} 4+[F(1,27)=8.44]$, but this was not true for the two control groups $(F<1)$. The threeway interaction between preexposure, conditioning treatment, and test day also fell just short of significance $[F(1,27)=3.49]$. Since this marginal three-way interaction suggests that the difference between Groups A12+ and $\mathrm{A} 12 \mathrm{C}$ may have been larger on the first pair of test days, we performed an additional analysis on the first set of difference scores. This ANOVA revealed no main effects $\left[F_{\max }(1,27)=2.73\right]$, but a significant interaction between preexposure and conditioning treatment $[F(1,27)=$ 7.89]. Analysis of simple effects confirmed that animals in Group $\mathrm{A} 12+$ drank more of the compound flavor than did those in Group $\mathrm{A} 12 \mathrm{C}[F(1,27)=7.52]$, while animals in Groups $\mathrm{A} 4+$ and $\mathrm{A} 4 \mathrm{C}$ drank similar amounts $[F(1,27)$ $=1.45]$. As before, difference scores were similar for the two control groups $(F<1)$, but were larger for Group $\mathrm{A} 12+$ than for Group $\mathrm{A} 4+[F(1,27)=10.32]$.

\section{GENERAL DISCUSSION}

The results of this set of four experiments appear to provide convincing evidence that exposure to two compound solutions, $\mathrm{AX}$ and $\mathrm{BX}$, followed by the conditioning of an aversion to A, is sufficient to establish $\mathrm{B}$ as a conditioned inhibitor of the US used to reinforce aversive conditioning. In Experiments 1 and 3, following such exposure, B was slow to acquire aversive properties when paired with the US itself; and in Experiments 2 and 4, B alleviated the aversion conditioned to another CS. Experiment 3 established that exposure to $A$ and $B$ in the absence of the common element, $X$, was not sufficient to generate such an effect, and Experiment 4 established that it required relatively prolonged exposure to $\mathrm{AX}$ and $\mathrm{BX}$. In every experiment, the results for the experimental group, $\mathrm{A}+$, were contrasted with those of a control group, A, that received no prior conditioning to $\mathrm{A}$, but that was otherwise treated identically. In Experiments 1-3, control animals were injected with saline following consumption of $\mathrm{A}$; in Experiment 4, half of the control animals received a lithium injection $24 \mathrm{~h}$ after drinking $\mathrm{A}$. It is difficult to see how this pattern of results is to be explained other than by saying that, after sufficient exposure to $A X$ and $B X$, excitatory conditioning to A results in inhibitory conditioning to $\mathrm{B}$. Since experimental and control groups had identical experience with $B$, it is not possible to attribute the retardation effect observed in Experiments 1 and 3 to differences in latent inhibition, nor the summation effect in Experiments 2 and 4 to differences in external inhibition or generalization decrement. Indeed, in Experiment 3, one would have expected Group A-B, exposed to B alone, to have shown, if anything, a stronger latent inhibition effect than Group AX-BX, exposed to B in compound with X: Honey and Hall (1988) found that latent inhibition to one flavor was attenuated if it was preexposed in compound with another (see Hall, 1991 for a discussion of related studies). And if the summation effect observed in Experiments 2 and 4 had been due to external inhibition, one would have expected a stronger effect in Group $\mathrm{A} 4+$ than in $\mathrm{A} 12+$, since the longer exposure to $\mathrm{B}$ in the latter group should have reduced any effect of external inhibition (cf. Reiss \& Wagner, 1972). Finally. in Experiments 1 and 3, it is conceivable that Groups $\mathrm{A}+$ and $\mathrm{AX}-\mathrm{BX}$ conditioned more slowly to $\mathrm{B}$ than the controls because, unlike the controls, they had received an earlier injection of lithium paired with A (although there is no reason to expect any such effect-see Mikulka, Leard, \& Klein, 1977); but it is difficult to see how this might have affected the summation results of Experiment 2, and the additional control group employed in Experiment 4 shows that this was not an important factor.

The theory of mediated generalization or acquired equivalence predicts that if two stımuli, $\mathrm{A}$ and $\mathrm{B}$, are both associated with a third common stimulus, $X$, this will enhance generalization between them (e.g., Honey \& Hall, i 989, 1991). Our results provide little evidence of such an effect. The results of Experiment 4 are consistent with the 
possibility that acquired equivalence might be the initial consequence of exposure to $\mathrm{AX}$ and $\mathrm{BX}$, but it is clear that it is reversed by prolonged exposure, and that such experience, rather than enhancing B's ability to elicit the same response as $\mathrm{A}$, has precisely the opposite effect.

Our experiments were prompted by the suggestion of McLaren et al. (1989) that prolonged exposure to two compound stimuli, AX and BX, might establish inhibitory associations between their unique elements, $A$ and $B$. But it is not at all obvious how such mutual inhibition between $A$ and $B$ should turn $B$ into a conditioned inhibitor of a US subsequently paired with $A$. One interpretation of such mutual inhibition would be to suppose that $B$ was now able to inhibit any representation of A otherwise evoked. But how would this generate the effects we have observed? One might conceivably argue that in Group A+ in Experiments 2 and 4, the suppression of intake elicited by the taste of quinine was partly mediated by quinine's tendency to evoke a representation of A (because they were both associated with a common aversive consequence), and that $\mathrm{B}$, by inhibiting this representation of A, alleviated that part of the suppression of intake mediated in this indirect way. The suggestion does not seem particularly plausible and is, anyway, unable to explain the retardation effect observed in Experiments 1 and 3. There, the problem is to explain how conditioning to A should result in slower conditioning to $\mathrm{B}$.

To our knowledge, no extant theory provides a mechanism for the effect reported in these two experiments. One potentially promising approach, however, would be to modify the activation rule used by McLaren et al. (1989) so as to permit negative activations. McClelland and Rumelhart (1985) provide one example of such a theory, which allows the activity of any unit to vary between +1 and -1 , rather than between +1 and 0 . The effect of this is that mutual inhibition between $A$ and $B$ would mean that positive activation of the units representing one stimulus would cause negative activation of the units representing the other stimulus. When A is paired with the US, therefore, the units representing $B$ take on negative activation values. This would then allow $B$ to acquire in- hibitory associations with the US (we are grateful to I. P. L. McLaren for this suggestion). Regardless of whether this analysis is worth pursuing, we believe that the results of the present experiments pose a significant challenge to associative theory.

\section{REFERENCES}

Hall, G. (1991). Perceptual and associative learning. Oxford: Oxford University Press, Clarendon Press.

Honey, R. C., \& HALL, G. (1988). Overshadowing and blocking procedures in latent inhibition. Quarterly Journal of Experimental Psychology, 40B, 163-186.

Honey, R. C., \& Hall, G. (1989). Acquired equivalence and distinctiveness of cues. Journal of Experimental Psychology: Animal Behavior Processes, 15, 338-346.

Honey, R. C., \& Hall, G. (1991). Acquired equivalence and distinctiveness of cues using a sensory-preconditioning procedure. Quarter/. Journal of Experimental Psychology, 43B, 121-135.

Mackintosh, N. J., Kaye, H., \& Bennett, C. H. (1991). Perceptual learning in flavour aversion conditioning. Quamerly Joumal of Experimental Psychology, 43B, 297-322.

MCClelland, J. L., \& Rumel hart, D. E. (1985). Distributed memory and the representation of general and specific memory. Joumal of $E x-$ perimental Psychology: General, 114, 159-188.

McLaren, I. P. L., Kaye, H., \& Mackintosh, N. J. (1989). An associative theory of the representation of stimuli: Applications to perceptual learning and latent inhibition. In. R. G. M. Morris (Ed.), Parallel distributed processing: Inplications for psuchology: and netwohiolog. (pp. 102-130). Oxford: Oxford University Press, Clarendon Press.

Mikulka, P. J., LeARd, B.. \& KLEIN. S. B. (1977). Jllness-alone exposure as a source of interference with the acquisition and retention of a taste aversion. Journal of Experimental Psychology. Arimal Beharior. Processes, 3, 189-201.

REISS, S., \& WAGNER, A. R. (1972). CS habituation produces a "latent inhibition effect" but no active "conditioned inhibition." Le'aming \& Motivation, 3, 237-245.

Rescorla, R. A., \& CunNingham. C. L. (1978). Within-compound flavor associations. Joumal of Experinentul Psichology: Animal Behavior Processes, 4, 267-275.

Rodrigo, T., Chamizo, V. D., Mclaren, I. P. L.. \& Mackiniosh, N. J. (1994). Effects of pre-exposure to the same or different pattern of extra-maze cues on subsequent extra-maze discrimination. Quarter/ly Journal of Experimental Psychology, 47B. 15-26.

(Manuscript received June 15, 1994; revision accepted for publication November 4 , 1994.) 